\title{
Ischemic Tolerance in Uremic Rabbits
}

\author{
John G. Kingma*, Guylaine Sénéchal, Jacques R. Rouleau, Iris Kingma \\ Faculté de Médecine Pavillon Ferdinand Vandry, Avenue de la Médecine, Université Laval Québec, Québec, \\ Canada \\ Email: "john.kingma@fmed.ulaval.ca
}

Received 6 October 2015; accepted 12 December 2015; published 15 December 2015

Copyright (C) 2015 by authors and Scientific Research Publishing Inc.

This work is licensed under the Creative Commons Attribution International License (CC BY). http://creativecommons.org/licenses/by/4.0/

(c) (i) Open Access

\section{Abstract}

Background: Cardiac complications after myocardial infarction are believed to be worse in the presence of comorbidities; we tested whether experimentally induced prolonged uremia exacerbated myocardial necrosis in a rabbit preparation of ischemia-reperfusion injury. In addition, we examined if treatment with an angiotensin converting enzyme inhibitor (Enalapril, ENA, $3 \mathrm{mg} / \mathrm{Kg}$, IV) could reduce post-ischemic myocardial damage. Methods: Prolonged uremia was induced by a two-stage subtotal nephrectomy and confirmed by marked increases in serum creatinine and urea levels; after 5 weeks, four groups of rabbits were exposed to 45-min acute coronary occlusion followed by 180 -min reperfusion. In treated animals, ENA was administered 5-min before onset of coronary reperfusion. All data from uremic animals were compared with time-matched controls. Results: Cardiac hemodynamics was similar for all groups during the development of kidney failure; heart rate in uremic rabbits was significantly lower for the duration of ischemia-reperfusion. In this animal model, the absence of coronary collateral circulation provides a stable ischemic substrate for evaluation of cellular necrosis. Infarct size (expressed as percent risk zone size) was: control, $48 \pm 16$; uremia, $36 \pm 5$; control + ENA, $51 \pm 19$; and uremia + ENA, $41 \pm 16$; risk zone size was similar for all animals. Conclusion: The present findings are inconsistent with the view that post-ischemic cardiac injury is greater in animals with pre-existent uremia. In addition, we were unable to show a significant beneficial effect with an angiotensin converting enzyme inhibitor on infarct size in either control or uremic rabbits. It remains to be proven in animal models with comorbidities such as manifest kidney disease that ischemic tolerance can be substantially reduced by either pharmacologic or non-pharmacologic interventions.

\section{Keywords}

Myocardial Infarct Size, Ischemia, Reperfusion, Uremia

\footnotetext{
"Corresponding author.
} 


\section{Introduction}

Myocardial infarction is a leading cause of morbidity and mortality in most industrialized countries. Cardiovascular risk is significantly higher in patients with kidney disease [1]; impaired renal function in patients with acute myocardial infarction is an important predictor of in-hospital mortality in these patients [2]-[5] being 2\% with normal renal function versus $\sim 30 \%$ in patients with end-stage renal disease.

Ischemic tolerance is thought to be diminished in the presence of co-morbidities such as kidney disease; in rodents, larger myocardial infarcts have been reported in most [6] [7], but not all [8], studies. In uremic hearts, cardiomyocytes are believed to be constantly close to the brink of ischemia [7]; however, myocardial protection against ischemia-reperfusion injury still appears possible. Similar findings results were recently reported in uremic rats subject to ischemia-reperfusion injury ex vivo [9]. Extent of infarction after acute ischemia is in part determined by the level of collateral blood flow within the ischemic zone [10]; considerable species differences have been documented with regard to coronary collateral circulation. The first goal of the present study was to evaluate infarct development in a rabbit model (poor coronary collateral flow) of prolonged uremia.

Coronary occlusion stimulates production of angiotensin II by the cardiac renin-angiotensin system [11] which can cause organ dysfunction [12] [13]. Angiotensin converting enzyme inhibitors (ACEI) blunt ischemic injury in most experimental animal models [14]-[17] but not all findings are positive [18]. In patients with heart failure, angiotensin receptor blockers (ARB) and ACEI reduce all-cause mortality associated with renal disorders [19] [20]; however, clinical benefit of combined ACEI and ARB treatments is mitigated [21]. The second goal was to examine if treatment with an ACEI (Enalapril) could reduce ischemic injury in uremic rabbits.

\section{Methods}

The animals used in these studies were maintained in accordance with the policies and guidelines of the Canadian Council on Animal Care. The protocol was approved by institutional animal care committee at Laval University.

Animals: Pathogen-free, healthy New-Zealand White male rabbits (2 - $3 \mathrm{Kg}$ body weight) from Charles River Laboratories were used for these studies. Animals were maintained in single cages under conditions of constant temperature and humidity and kept on a strict 12:12 h dark-light cycle; they had free access to food (comprising 17.7\% crude protein, 3.3\% fat and 13.7\% crude fiber; (Harlan Laboratories Inc., Montreal, QC) and water; animals were not pair fed.

Surgical and experimental procedures: After 1 week acclimatization, rabbits underwent a two-stage surgical subtotal nephrectomy or sham operation; briefly, rabbits were pre-medicated with acepromazine maleate (Atravet, $2 \mathrm{mg} / \mathrm{Kg}$, i.m.) after establishment of a venous access via a butterfly needle catheter on a marginal ear vein animals were anesthetized with sodium pentobarbital ( $25 \mathrm{mg} / \mathrm{Kg}$, i.v.). Butorphanol ( $0.22 \mathrm{mg} / \mathrm{Kg}$, i.m.) was administered preoperatively for analgesia and repeated every $12 \mathrm{~h}$ for the first $48 \mathrm{~h}$ postoperatively. Aseptic techniques were used for surgery; subtotal nephrectomy was performed through a flank incision. Approximately 70 percent of the left kidney was removed by excision of upper and lower poles (excessive blood loss was limited by application of gelatin sponges and light pressure) [22]. The flank incision was closed and 7 days later, the right kidney was removed. Following repair of the flank incision, the uremia phenotype was allowed to develop over a 5-week period; serum creatinine and uric acid levels were measured weekly. The kidney ablation model described herein is considered a low-renin model of the phenotype [23]. Time-matched sham control (CTR) rabbits underwent the same surgical procedure but kidneys were only gently manipulated and left intact.

After 5-weeks, rabbits were subject to ischemia-reperfusion injury as described in previous studies from our laboratory [24]-[26]. For these studies, rabbits were pre-medicated with acepromazine maleate (Atravet, $2 \mathrm{mg} /$ $\mathrm{Kg}$, i.m.) and anesthetized with sodium pentobarbital $(25 \mathrm{mg} / \mathrm{Kg}$, i.v.); additional anesthetic was provided hourly. Via a mid-line cervical incision, the trachea was cannulated and rabbits were mechanically ventilated (MD Industries, Theodore, AL, USA) with oxygen enriched air; ventilation rate was maintained between 28 - 30 breaths/min. A catheter (5Fr) was placed in the right jugular vein for administration of drugs and fluids. A cannula (PE-90) was advanced via the carotid artery to the left ventricle and then pulled back into the aortic root to obtain phasic arterial pressures (systolic/diastolic). The heart was exposed by left thoracotomy and a snare (4 - 0 silk) was placed around the first anterolateral branch of the left circumflex coronary artery (midway between the atrioventricular groove and apex). The silk suture was passed through a length of Tygon tubing; regional coronary occlusion was induced by clamping the suture (mosquito hemostat). Ischemia was verified visually by ap- 
pearance of regional epicardial cyanosis and elevation of the ST segment electrocardiogram (lead II). Hearts that developed ventricular fibrillation were successfully cardioverted by gentle flicking of the left ventricle (electrical cardioversion was not used). Lead II electrocardiogram and arterial pressures were recorded continuously throughout the experiments on a 4-channel EasyGraf ${ }^{\mathrm{TM}}$ recorder (TA-240 Gould Instruments, Montreal, QC). Body temperature was monitored with a rectal thermometer and maintained within normal limits using external heating pads.

Thirty minutes after completion of the surgical procedures, rabbits underwent a 45-min coronary artery occlusion followed by 180-min reperfusion. Rabbits were allocated (no randomization due to the prerequisite for development of the uremic phenotype) to four experimental groups: 1-CTR given saline $(n=6), 2$-uremia (UR) given saline ( $(\mathrm{=}=8)$, 3-CTR + ENA given Enalapril (Vasotec; $3 \mathrm{mg} / \mathrm{Kg}, \mathrm{IV}, \mathrm{n}=8$ ) and 4-UR + ENA given Enalapril (Vasotec; $3 \mathrm{mg} / \mathrm{Kg}, \mathrm{IV}, \mathrm{n}=8$ ). Drug treatments were initiated 2-min prior to the onset of coronary reperfusion. Prospective exclusion criteria were 1-death prior to completion of the study or 2-risk zone $<10$ percent of LV area.

Analysis of infarct size and risk zone: At the end of the study, under deep anesthesia, each animal was sacrificed by intravenous injection of saturated potassium chloride $(10 \mathrm{~mL})$. Risk zone size was demarcated after re-ligation of the infarct-related artery by intra-atrial injection of Monastral blue dye (5\% solution); the heart was then extirpated, placed on a Langendorff perfusion apparatus and perfused with 2,3,5-triphenyltetrazolium chloride (at $75 \mathrm{mmHg}$ and $37^{\circ} \mathrm{C}$ ). After 20-min the right atria and right ventricle were dissected and discarded, the LV was weighed and fixed by immersion in buffered $10 \%$ formalin. Coronary collateral blood flow within the risk region was not assessed since it is minimal in rabbit myocardium [10]. Risk zone, infarct zone and total LV area were measured and calculated as previously described [26].

Data analyses: All statistical comparisons were done using SAS (SAS Institute, Cary, NC, USA). Heart weight, infarct size, area at risk and infarct area were compared using a Student's $t$ test. Intergroup comparisons for blood biochemistry and cardiac hemodynamics were made using ANOVA for repeated measures. Statistical tests were considered significant if the $p$ value was $\leq 0.05$. Heart rate-blood pressure product was used as an index of myocardial oxygen demand.

\section{Results}

Thirty-five rabbits were entered into this study; final statistical analyses were done with data from 30 rabbits; five rabbits died before completing the study but no differences in mortality between sham-operated and uremic animals were detected. Blood urea-nitrogen ( $30.5 \pm 10.2$ vs $6.6 \pm 1.2 \mathrm{mM} / \mathrm{L})$ and serum creatinine (265 $\pm 46 \mathrm{vs}$ $114 \pm 15 \mu \mathrm{M} / \mathrm{L}$ ) levels 5-weeks after subtotal nephrectomy were significantly higher for UR rabbits (compared to CTR) as expected; serum potassium levels ( $3.1 \pm 0.4 \mathrm{vs} 3.3 \pm 0.2 \mathrm{mM} / \mathrm{L}$ ) were stable over this period.

Hemodynamic variables are summarized in Table 1. Baseline (i.e. prior to coronary occlusion) heart rates were similar in all groups; heart rate in UR rabbits was markedly lower during coronary occlusion and progressively decreased during reperfusion. A similar pattern for heart rate was observed in the UR + ENA group. Systolic and diastolic arterial blood pressure was well conserved in uremic rabbits but decreased substantially in CTR animals; this parameter was maintained in both groups administered ENA during reperfusion. Rate-pressure product (determinant of myocardial oxygen demand) showed no significant difference between experimental groups (see Figure 1). In addition, a significant correlation between infarct size (normalized to risk area) and heart rate-blood pressure product (Figure 2) was not seen.

Heart weight, LV area, risk and infarct zone volume and infarct size for all experimental groups are reported in Table 2. There was no significant difference in infarct size, expressed as percent of risk zone size between CTR (48\% $\pm 16 \%)$ and UR (36\% $\pm 5 \%$ ) rabbits (see Figure 3(a)). In animals given Enalapril (see Figure 3(b)), infarct size was $51 \% \pm 19 \%$ vs $41 \% \pm 16 \%(\mathrm{p}=$ NS) in CTR and UR groups, respectively. Smaller infarcts in UR rabbits were not due to lower oxygen demands in this group.

\section{Discussion}

Clinical outcomes in patients with chronic kidney disease that suffer an acute myocardial infarction are dismal [27] [28]. Risk of cardiac disease and its associated complications augment in relation to advancing stages of kidney disease [29]. In the experimental model of kidney injury produced by subtotal nephrectomy followed by acute myocardial ischemia-reperfusion injury used here, we report that infarct size is comparable between 
Table 1. Summary of hemodynamic data.

\begin{tabular}{|c|c|c|c|c|c|c|}
\hline & $\operatorname{CTR}(n=6)$ & UR $(n=8)$ & $p$ & CTR + ENA $(n=8)$ & UR + ENA $(n=8)$ & $p$ \\
\hline \multicolumn{7}{|l|}{ HR, bpm } \\
\hline Pre-occlusion & $286 \pm 28$ & $262 \pm 18$ & 0.477 & $281 \pm 33$ & $272 \pm 18$ & 0.182 \\
\hline 30-min CO & $276 \pm 18$ & $221 \pm 33$ & $<0.003$ & $262 \pm 34$ & $214 \pm 38$ & $<0.020$ \\
\hline 30-min REP & $277 \pm 15$ & $206 \pm 31$ & $<0.001$ & $256 \pm 27$ & $216 \pm 30$ & $<0.013$ \\
\hline 60-min REP & $258 \pm 24$ & $185 \pm 10$ & $<0.001$ & $260 \pm 16$ & $207 \pm 26$ & $<0.002$ \\
\hline 120-min REP & $279 \pm 23$ & $157 \pm 24$ & $<0.001$ & $242 \pm 28$ & $181 \pm 21$ & $<0.001$ \\
\hline 180-min REP & $219 \pm 34$ & $138 \pm 24$ & $<0.001$ & $226 \pm 25$ & $161 \pm 18$ & $<0.001$ \\
\hline \multicolumn{7}{|l|}{$\mathrm{PA}_{0} \mathrm{~S}, \mathrm{~mm} \mathrm{Hg}$} \\
\hline Pre-occlusion & $117 \pm 13$ & $102 \pm 16$ & 0.489 & $98 \pm 21$ & $102 \pm 16$ & 0.698 \\
\hline 30-min CO & $87 \pm 18$ & $101 \pm 39$ & 0.419 & $86 \pm 18$ & $85 \pm 18$ & 0.869 \\
\hline 30-min REP & $94 \pm 10$ & $103 \pm 42$ & 0.345 & $93 \pm 11$ & $101 \pm 24$ & 0.377 \\
\hline 60-min REP & $92 \pm 15$ & $110 \pm 23$ & 0.123 & $94 \pm 13$ & $103 \pm 26$ & 0.421 \\
\hline 120-min REP & $95 \pm 12$ & $108 \pm 35$ & 0.387 & $97 \pm 12$ & $101 \pm 35$ & 0.785 \\
\hline 180-min REP & $96 \pm 15$ & $110 \pm 31$ & 0.339 & $99 \pm 11$ & $103 \pm 35$ & 0.742 \\
\hline \multicolumn{7}{|l|}{$\mathrm{PA}_{0} \mathrm{D}, \mathrm{mm} \mathrm{Hg}$} \\
\hline Pre-occlusion & $100 \pm 9$ & $82 \pm 21$ & 0.228 & $82 \pm 19$ & $82 \pm 21$ & 0.981 \\
\hline 30-min CO & $65 \pm 17$ & $85 \pm 33$ & 0.203 & $65 \pm 17$ & $67 \pm 17$ & 0.886 \\
\hline 30-min REP & $75 \pm 11$ & $88 \pm 37$ & 0.425 & $72 \pm 11$ & $84 \pm 20$ & 0.164 \\
\hline 60-min REP & $79 \pm 13$ & $94 \pm 23$ & 0.173 & $74 \pm 7$ & $87 \pm 25$ & 0.187 \\
\hline 120-min REP & $77 \pm 10$ & $92 \pm 27$ & 0.232 & $76 \pm 8$ & $86 \pm 35$ & 0.574 \\
\hline 180-min REP & $81 \pm 12$ & $94 \pm 25$ & 0.263 & $79 \pm 9$ & $87 \pm 35$ & 0.599 \\
\hline
\end{tabular}

Data are mean \pm 1 SD. HR: heart rate; $\mathrm{PA}_{0} \mathrm{~S}, \mathrm{PA}_{0} \mathrm{D}$ : systolic, diastolic arterial pressure; CTR: control; UR: uremia; ENA: enalapril; CO: coronary occlusion; REP: coronary reperfusion.

Table 2. Effects of UR on infarct size.

\begin{tabular}{|c|c|c|c|c|c|c|}
\hline & CTR & UR & $p$ & CTR + ENA & UR + ENA & $p$ \\
\hline Heart wt (g) & $6.0 \pm 2.0$ & $6.1 \pm 0.77$ & 0.991 & $5.11 \pm 0.41$ & $6.3 \pm 1.6$ & 0.984 \\
\hline LV area $\left(\mathrm{mm}^{2}\right)$ & $32.3 \pm 8.3$ & $32.5 \pm 3.8$ & 0.752 & $29.8 \pm 2.8$ & $31.9 \pm 3.4$ & 0.458 \\
\hline $\mathrm{AN}\left(\mathrm{cm}^{3}\right)$ & $1.05 \pm 0.73$ & $0.48 \pm 0.15$ & 0.062 & $0.61 \pm 0.17$ & $0.72 \pm 0.40$ & 0.318 \\
\hline $\operatorname{AR}\left(\mathrm{cm}^{3}\right)$ & $2.23 \pm 1.16$ & $1.62 \pm 0.58$ & 0.137 & $1.29 \pm 0.32$ & $1.73 \pm 0.59$ & 0.140 \\
\hline AN/AR (\%) & $48 \pm 16$ & $36 \pm 5$ & 0.108 & $51 \pm 19$ & $41 \pm 16$ & 0.405 \\
\hline
\end{tabular}

Data are mean $\pm 1 \mathrm{SD}$; AN: infarct area volume; AR: risk area volume; AN/AR: infarct size; CTR: controls; UR: uremia; ENA: enalapril.

matched control and kidney failure rabbits. In addition, we were unable to show significant reduction of ischemic injury in animals treated with Enalapril just prior to the onset of coronary reperfusion. This experimental model shows some similarity, albeit with limitations, to the human cardio-renal syndrome phenotype that is currently the subject of considerable discussion [30]-[32]. The rabbit subtotal nephrectomy renal failure model has been used, though infrequently, in studies on erythropoietin [33] and amino acid [34] metabolism and erectile dysfunction [35].

Earlier studies almost unanimously report that myocardial infarct size is greater in uremic animal models [6] [7]; exposure to renal failure in those studies was shorter than in the present study. However, Kocsis and coworkers recently reported in rats that myocardial infarct size was not significantly affected by prolonged uremia 


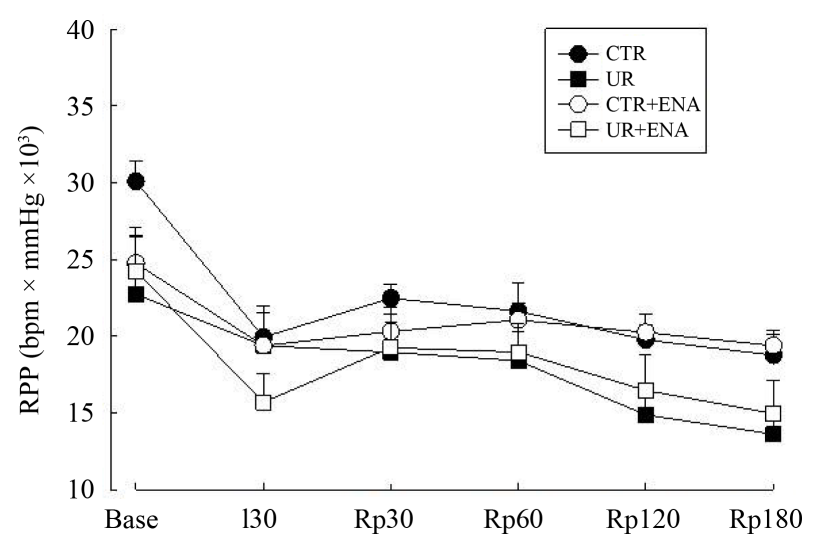

Figure 1. Time course of changes in rate-pressure product (RPP) during the experimental protocol in control (CTR), uremic (UR), CTR + ENA and UR + ENA rabbits. Data are expressed as means $\pm \mathrm{SEM} ;{ }^{*} p \leq 0.05$ versus baseline values in respective experimental groups.

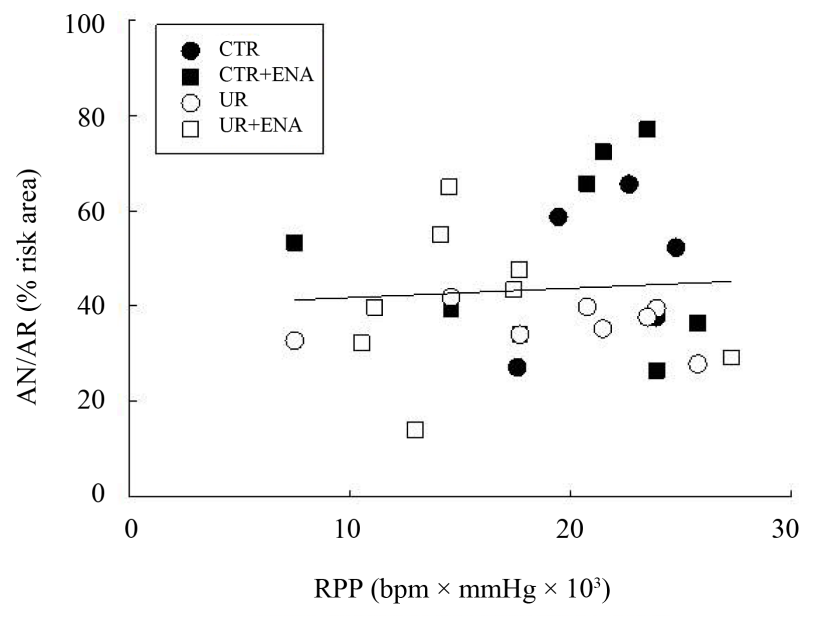

Figure 2. Scattergram showing relation between area of necrosis (AN) as a percentage of area at risk (AR) and rate-pressure product (RPP) for CTR, UR, CTR + ENA and UR + ENA groups. Smaller infarcts were not a result of lower myocardial oxygen demand.

[9]. Our findings are in agreement with those data since they show a comparable level of infarction between control and uremic rabbits; potential confounding factors such as risk zone size, cardiac hemodynamics and oxygen demand that contributed to infarct development were not different between experimental groups.

Of note in the present study is the significant reduction in heart rate that is accompanied by a slight increase in arterial pressures in uremic animals after the onset of acute ischemia. The physiopathological mechanisms responsible remain unclear but warrant further investigation. In uremic patients, neuropathy of the autonomic nervous system is in conjunction with heart disease, hypertension and anemia modulate baroreceptor responses [36] [37]; however, the nature of these relationships remains unclear. Neuropathy of the autonomic nervous system is also produced by elevated serum uric acid levels. Lower oxygen demand in uremic animals during ischemia and reperfusion might also have contributed to limited extent of injury; however, better perfusion of the ischemic region after reperfusion due to maintained arterial pressures might explain the smaller infarcts.

A key feature of the uremic cardiac phenotype is the presence of LV hypertrophy [38] [39]. In this context, intermyocyte fibrosis and capillary rarefaction are amplified thereby bringing myocytes closer to the brink of ischemia (due to poor oxygen delivery, reduced capillary density and greater oxygen diffusion distance). 


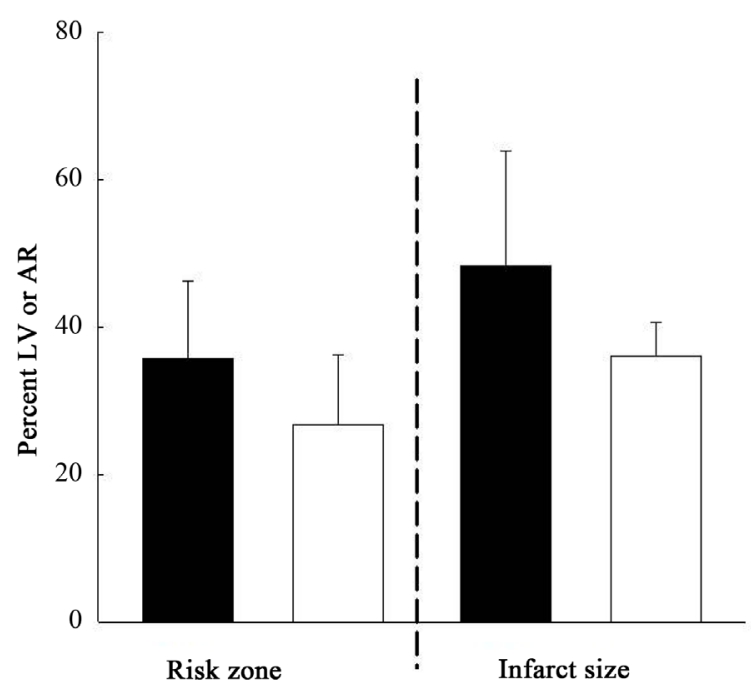

(a)

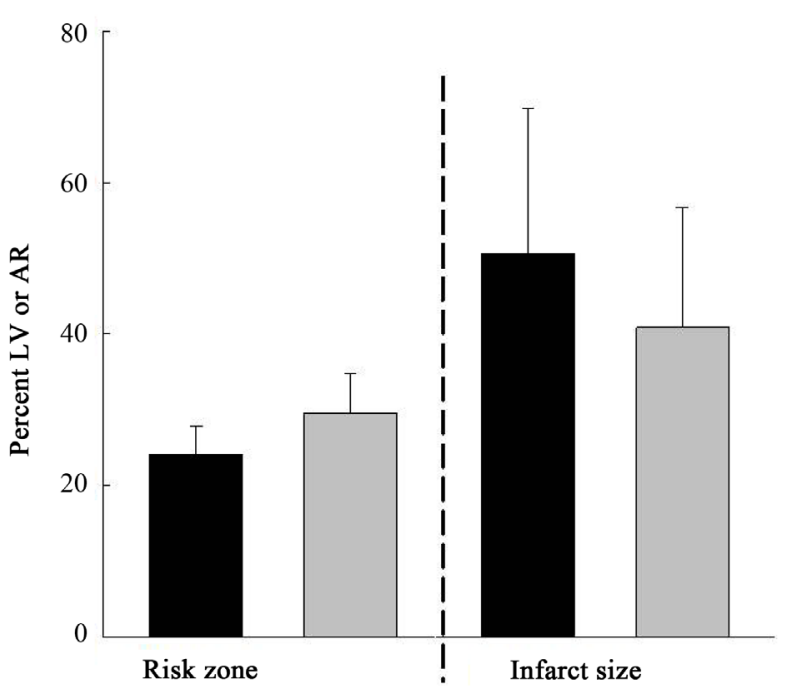

(b)

Figure 3. Risk zone size (as a percentage of LV area) and AN/AR (as percentage of AR) for (a): CTR (filled bars) and UR (open bars) rabbits, and (b): CTR + ENA (filled bars) and UR + ENA (grey bars) rabbits exposed to ischemia-reperfusion injury. Results are means $\pm 1 \mathrm{SD}$.

Histologic evaluations of LV geometry were not done in the present study; interestingly heart weight and total LV cross-sectional area were not significantly changed during the experimental timeline but we would expect these results to change with longer durations of prolonged uremia. Body weight, another indicator of renal insufficiency was not measured in this study; however, we [40] and others [9] [41] have reported little variation between control and uremic animals in different species particularly in the early stages (i.e. $<6$ weeks) after onset of kidney insufficiency. Coronary collateral blood flow, another major determinant of infarct size was not considered in this experimental model as it was almost non-existent in rabbit myocardium [10]. As such, the different mechanisms through which progressive kidney disease influences myocardial sensitivity to ischemia require further study.

The physiopathology of reno-cardiac syndrome is complex; reduced perfusion of the kidneys stimulates the renin-angiotensin-aldosterone system and induces vasoconstriction which contributes to increased afterload and an overall reduction in cardiac output. Additionally, angiotensin II has been shown to stimulate synthesis of pro-inflammatory cytokines that contribute to cardiac hypertrophy and vessel dysfunction [12] [42]. Angiotensin converting enzyme inhibitors have, for the most part, been shown to significantly mitigate ischemic injury via different pathways in animal studies of acute myocardial ischemia-reperfusion injury [43]-[45]; however, none have been done in animals with pre-existing kidney disease. In the present study, rabbits were given Enalapril acutely prior to onset of coronary reperfusion; the extent of necrosis was similar for all animals treated with Enalapril. The principal goal of this study was to examine whether infarct size could be modulated in animals with impaired renal function. Byrne et al. [7] recently documented that ischemic conditioning markedly attenuated tissue necrosis in uremic rats; they speculated that uremic animals derived greater advantage by conditioning strategies compared to non-uremic animals. Conditioning mediated protection can be achieved, in part, by modulation of key intracellular signalling cascades [46]-[48] or related pathways. Thus, while intracellular signal transduction may be adversely affected by higher levels of catabolic toxins associated with kidney failure essential rescue pathways that contribute to cytoprotection continue to function.

Certain limitations of these studies should be mentioned. First, subtotal nephrectomy resulted in a sustained increase in serum creatinine and blood urea levels; both are considered biomarkers of renal dysfunction and are commonly used in the clinic. Plasma renin increases transiently in animals with sub-total nephrectomy [41] [49] but was not measured in the present study. The relatively short duration of renal failure in this or similar models is also insufficient to lead to longer term cardiovascular changes in chronic kidney disease in humans due to hypertension, hyperlipidemia, hyperphosphatemia, vascular calcification and diabetes. Body weight changes were not determined; published results for this parameter are variable as discussed earlier. However, development of 
treatments (pharmacologic or other) for patients with reno-cardiac syndrome ultimately depends on our ability to create appropriate experimental models for testing recognized mechanisms individually. The experimental procedures and evaluation criteria for measurement of infarct size used in this preclinical study follow recent guidelines of the CAESAR (Consortium for preclinical assessment of cardioprotective therapies) sponsored by the NHLBI, with the exception that we did not do a histology assessment of tissue injury within ischemic and non-ischemic myocardium [50]. Finally, Enalapril administered at a single dosage and given prior to coronary reperfusion was evaluated in these experiments (a full pharmacologic profiling or dose-response evaluation to establish optimal dosage for cardioprotection was not performed). Anti-ischemic effects of ACEI have been reported in healthy, animal preparations of cardiac ischemia-reperfusion injury [18] [51] [52]. The inability to limit cardiac injury with Enalapril might be due to the fact that the renin-angiotensin II system in the myocardium was not activated during prolonged uremia; the model used here is essentially a low-renin preparation. However, inability to detect renin in the plasma does not completely exclude its participation in renin-angiotensin pathways [53].

Improved understanding of bidirectional interactions between the heart and kidney should help in translation of novel experimental treatments to the growing numbers of patients afflicted with cardio-renal syndrome. We report here that post-ischemic myocardial damage is not exacerbated in rabbits with kidney dysfunction. Moreover, treatment with Enalapril did not reduce infarct size in uremic animals. It is not clear whether this is due to an inability to achieve an ischemia threshold in uremic animals but this argument has been used to explain cardioprotection by different organ conditioning stratagems. Further evaluation of pharmacologic and non-pharmacologic interventions in experimental models with comorbidities such as reno-cardiac syndrome is recommended particularly in those with late stages of renal failure. We believe that the prolonged uremia model described herein provides a reliable tool for physiopathological evaluation of reno-cardiac interactions.

\section{Acknowledgements}

The authors thank the animal care staff at the Research Center for their valuable help during these studies which were supported by the Heart and Stroke Foundation of Quebec (JGK) and Kidney Foundation of Canada (IK). Statistical analyses were performed by Serge Simard.

\section{Disclosures}

The authors have no financial or other interests to disclose.

\section{References}

[1] Gansevoort, R.T., Correa-Rotter, R., Hemmelgarn, B.R., Jafar, T.H., Heerspink, H.J., Mann, J.F., Matsushita, K. and Wen, C.P. (2013) Chronic Kidney Disease and Cardiovascular Risk: Epidemiology, Mechanisms, and Prevention. The Lancet, 382, 339-352. http://dx.doi.org/10.1016/S0140-6736(13)60595-4

[2] Smith, G.L., Lichtman, J.H., Bracken, M.B., Shlipak, M.G., Phillips, C.O., DiCapua, P. and Krumholz, H.M. (2006) Renal Impairment and Outcomes in Heart Failure: Systematic Review and Meta-Analysis. Journal of the American College of Cardiology, 47, 1987-1996. http://dx.doi.org/10.1016/j.jacc.2005.11.084

[3] Smith, G.L., Masoudi, F.A., Shlipak, M.G., Krumholz, H.M. and Parikh, C.R. (2008) Renal Impairment Predicts Long-Term Mortality Risk after Acute Myocardial Infarction. Journal of the American Society of Nephrology, 19, 141150. http://dx.doi.org/10.1681/ASN.2007050554

[4] Shlipak, M.G., Heidenreich, P.A., Noguchi, H., Chertow, G.M., Browner, W.S. and McClellan, M.B. (2002) Association of Renal Insufficiency with Treatment and Outcomes after Myocardial Infarction in Elderly Patients. Annals of Internal Medicine, 137, 555-562. http://dx.doi.org/10.7326/0003-4819-137-7-200210010-00006

[5] Wright, R.S., Reeder, G.S., Herzog, C.A., Albright, R.C., Williams, B.A., Dvorak, D.L., Miller, W.L., Murphy, J.G., Kopecky, S.L. and Jaffe, A.S. (2002) Acute Myocardial Infarction and Renal Dysfunction: A High-Risk Combination. Annals of Internal Medicine, 137, 563-570. http://dx.doi.org/10.7326/0003-4819-137-7-200210010-00007

[6] Dikow, R., Kihm, L.P., Zeier, M., Kapitza, J., Tornig, J., Amann, K., Tiefenbacher, C. and Ritz, E. (2004) Increased Infarct Size in Uremic Rats: Reduced Ischemia Tolerance? Journal of the American Society of Nephrology, 15, 15301536. http://dx.doi.org/10.1097/01.ASN.0000130154.42061.C6

[7] Byrne, C.J., McCafferty, K., Kieswich, J., Harwood, S., Andrikopoulos, P., Raftery, M., Thiemermann, C. and Yaqoob, M.M. (2012) Ischemic Conditioning Protects the Uremic Heart in a Rodent Model of Myocardial Infarction. Circula- 
tion, 125, 1256-1265. http://dx.doi.org/10.1161/CIRCULATIONAHA.111.055392

[8] Bongartz, L.G., Joles, J.A., Verhaar, M.C., Cramer, M.J., Goldschmeding, R., Tilburgs, C., Gaillard, C.A., Doevendans, P.A. and Braam, B. (2012) Subtotal Nephrectomy Plus Coronary Ligation Leads to More Pronounced Damage in Both Organs than Either Nephrectomy or Coronary Ligation. American Journal of Physiology - Heart and Circulatory Physiology, 302, H845-H854. http://dx.doi.org/10.1152/ajpheart.00261.2011

[9] Kocsis, G.F., Sarkozy, M., Bencsik, P., Pipicz, M., Varga, Z.V., Paloczi, J., Csonka, C., Ferdinandy, P. and Csont, T. (2012) Preconditioning Protects the Heart in a Prolonged Uremic Condition. American Journal of Physiology-Heart and Circulatory Physiology, 303, H1229-H1236. http://dx.doi.org/10.1152/ajpheart.00379.2012

[10] Maxwell, M.P., Hearse, D.J. and Yellon, D.M. (1987) Species Variation in the Coronary Collateral Circulation during Regional Myocardial Ischemia: A Critical Determinant of the Rate of Evolution and Extent of Myocardial Infarction. Cardiovascular Research, 21, 737-746. http://dx.doi.org/10.1093/cvr/21.10.737

[11] Ertl, G., Alexander, R.W. and Kloner, R.A. (1983) Interactions between Coronary Occlusion and the Renin-Angiotensin System in the Dog. Basic Research in Cardiology, 78, 518-533. http://dx.doi.org/10.1007/BF01906463

[12] Remuzzi, G., Perico, N., Macia, M. and Ruggenenti, P. (2005) The Role of Renin-Angiotensin-Aldosterone System in the Progression of Chronic Kidney Disease. Kidney International, 68, S57-S65.

http://dx.doi.org/10.1111/j.1523-1755.2005.09911.x

[13] Swedberg, K., Eneroth, P., Kjekshus, J. and Wilhelmsen, L. (1990) Hormones Regulating Cardiovascular Function in Patients with Severe Congestive Heart Failure and Their Relation to Mortality. CONSENSUS Trial Study Group. Circulation, 82, 1730-1736. http://dx.doi.org/10.1161/01.CIR.82.5.1730

[14] Ertl, G., Kloner, R.A., Alexander, R.W. and Braunwald, E. (1982) Limitation of Experimental Infarct Size by an Angiotensin-Converting Enzyme Inhibitor. Circulation, 65, 40-48. http://dx.doi.org/10.1161/01.CIR.65.1.40

[15] Mehta, P.M., Alker, K.J. and Kloner, R.A. (1988) Functional Infarct Expansion, Left Ventricular Dilation and Isovolumic Relaxation Time after Coronary Occlusion: A Two-Dimensional Echocardiographic Study. Journal of the American College of Cardiology, 11, 630-636. http://dx.doi.org/10.1016/0735-1097(88)91542-2

[16] De Graeff, P.A., Van Gilst, W.H., Bel, K., de Langen, C.D., Kingma, J.H. and Wesseling, H. (1987) Concentration-Dependent Protection by Captopril against Myocardial Damage during Ischemia and Reperfusion in a Closed Chest Pig Model. Journal of Cardiovascular Pharmacology, 9, S37-S42. http://dx.doi.org/10.1097/00005344-198700002-00009

[17] Parlakpinar, H., Ozer, M.K. and Acet, A. (2011) Effects of Captopril and Angiotensin II Receptor Blockers (AT1, AT2) on Myocardial Ischemia-Reperfusion Induced Infarct Size. Cytokine, 56, 688-694. http://dx.doi.org/10.1016/j.cyto.2011.09.002

[18] Daniell, H.B., Carson, R.R., Ballard, K.D., Thomas, G.R. and Privitera, P.J. (1984) Effects of Captopril on Limiting Infarct Size in Conscious Dogs. Journal of Cardiovascular Pharmacology, 6, 1043-1047. http://dx.doi.org/10.1097/00005344-198411000-00009

[19] Brenner, B.M., Cooper, M.E., de Zeeuw, D., Keane, W.F., Mitch, W.E., Parving, H.H., Remuzzi, G., Snapinn, S.M., Zhang, Z. and Shahinfar, S. (2001) Effects of Losartan on Renal and Cardiovascular Outcomes in Patients with Type 2 Diabetes and Nephropathy. The New England Journal of Medicine, 345, 861-869. http://dx.doi.org/10.1056/NEJMoa011161

[20] Edner, M., Benson, L., Dahlstrom, U. and Lund, L.H. (2015) Association between Renin-Angiotensin System Antagonist Use and Mortality in Heart Failure with Severe Renal Insufficiency: A Prospective Propensity Score-Matched Cohort Study. European Heart Journal, 36, 2318-2326. http://dx.doi.org/10.1093/eurheartj/ehv268

[21] Fried, L.F., Emanuele, N., Zhang, J.H., Brophy, M., Conner, T.A., Duckworth, W., Leehey, D.J., McCullough, P.A., O’Connor, T., Palevsky, P.M., Reilly, R.F., Seliger, S.L., Warren, S.R., Watnick, S., Peduzzi, P. and Guarino, P. (2013) Combined Angiotensin Inhibition for the Treatment of Diabetic Nephropathy. The New England Journal of Medicine, 369, 1892-1903. http://dx.doi.org/10.1056/NEJMoa1303154

[22] Brochu, E., Lacasse, S., Lariviere, R., Kingma, I., Grose, J.H. and Lebel, M. (1999) Differential Effects of Endothelin-1 Antagonists on Erythropoietin-Induced Hypertension in Renal Failure. Journal of the American Society of Nephrology, 10, 1440-1446.

[23] Freundlich, M., Quiroz, Y., Zhang, Z., Zhang, Y., Bravo, Y., Weisinger, J.R., Li, Y.C. and Rodriguez-Iturbe, B. (2008) Suppression of Renin-Angiotensin Gene Expression in the Kidney by Paricalcitol. Kidney International, 74, $1394-1402$. http://dx.doi.org/10.1038/ki.2008.408

[24] Daleau, P., Boudriau, S., Michaud, M., Jolicoeur, C. and Kingma Jr., J.G. (2001) Preconditioning in the Absence or Presence of Sustained Ischemia Modulates Myocardial Cx43 Protein Levels and Gap Junction Distribution. Canadian Journal of Physiology and Pharmacology, 79, 371-378. http://dx.doi.org/10.1139/y01-004 
[25] Currie, R.W., Tanguay, R.M. and Kingma Jr., J.G. (1993) Heat-Shock Response and Limitation of Tissue Necrosis during Occlusion/Reperfusion in Rabbit Hearts. Circulation, 87, 963-971. http://dx.doi.org/10.1161/01.CIR.87.3.963

[26] Kingma Jr., J.G., Simard, D., Rouleau, J.R., Tanguay, R.M. and Currie, R.W. (1996) Effect of 3-Aminotriazole on Hyperthermia-Mediated Cardioprotection in Rabbits. American Journal of Physiology: Heart and Circulatory Physiology, 270, H1165-H1171.

[27] Anavekar, N.S., McMurray, J.J., Velazquez, E.J., Solomon, S.D., Kober, L., Rouleau, J.L., White, H.D., Nordlander, R., Maggioni, A., Dickstein, K., Zelenkofske, S., Leimberger, J.D., Califf, R.M. and Pfeffer, M.A. (2004) Relation between Renal Dysfunction and Cardiovascular Outcomes after Myocardial Infarction. The New England Journal of Medicine, 351, 1285-1295. http://dx.doi.org/10.1056/NEJMoa041365

[28] de Mattos, A.M., Siedlecki, A., Gaston, R.S., Perry, G.J., Julian, B.A., Kew, C.E., Deierhoi, M.H., Young, C., Curtis, J.J. and Iskandrian, A.E. (2008) Systolic Dysfunction Portends Increased Mortality among Those Waiting for Renal Transplant. Journal of the American Society of Nephrology, 19, 1191-1196. http://dx.doi.org/10.1681/ASN.2007040503

[29] Go, A.S., Chertow, G.M., Fan, D., McCulloch, C.E. and Hsu, C.Y. (2004) Chronic Kidney Disease and the Risks of Death, Cardiovascular Events, and Hospitalization. The New England Journal of Medicine, 351, 1296-1305. http://dx.doi.org/10.1056/NEJMoa041031

[30] Braam, B., Joles, J.A., Danishwar, A.H. and Gaillard, C.A. (2014) Cardiorenal Syndrome-Current Understanding and Future Perspectives. Nature Reviews Nephrology, 10, 48-55. http://dx.doi.org/10.1038/nrneph.2013.250

[31] Bongartz, L.G., Cramer, M.J., Doevendans, P.A., Joles, J.A. and Braam, B. (2005) The Severe Cardiorenal Syndrome: “Guyton Revisited”. European Heart Journal, 26, 11-17. http://dx.doi.org/10.1093/eurheartj/ehi020

[32] Ronco, C., McCullough, P., Anker, S.D., Anand, I., Aspromonte, N., Bagshaw, S.M., Bellomo, R., Berl, T., Bobek, I., Cruz, D.N., Daliento, L., Davenport, A., Haapio, M., Hillege, H., House, A.A., Katz, N., Maisel, A., Mankad, S., Zanco, P., Mebazaa, A., Palazzuoli, A., Ronco, F., Shaw, A., Sheinfeld, G., Soni, S., Vescovo, G., Zamperetti, N. and Ponikowski, P. (2010) Cardio-Renal Syndromes: Report from the Consensus Conference of the Acute Dialysis Quality Initiative. European Heart Journal, 31, 703-711. http://dx.doi.org/10.1093/eurheartj/ehp507

[33] Brown, J.H., Lappin, T.R., Elder, G.E., Bridges, J.M. and McGeown, M.G. (1990) The Metabolism of Erythropoietin in the Normal and Uraemic Rabbit. Nephrology Dialysis Transplantation, 5, 855-859. http://dx.doi.org/10.1093/ndt/5.10.855

[34] Oreopoulos, A.K., Balaskas, E.V., Rodela, H., Anderson, G.H. and Oreopoulos, D.G. (1993) An Animal Model for the Study of Amino Acid Metabolism in Uremia and during Peritoneal Dialysis. Peritoneal Dialysis International, 13, S499-S507.

[35] Bagcivan, I., Kilicarslan, H., Sarac, B., Gokce, G., Yildirim, S., Ayan, S. and Sarioglu, Y. (2003) The Evaluation of the Effects of Renal Failure on Erectile Dysfunction in a Rabbit Model of Chronic Renal Failure. BJU International, 91, 697-701. http://dx.doi.org/10.1046/j.1464-410X.2003.04179.x

[36] Lazarus, J.M., Hampers, C.L., Lowrie, E.G. and Merrill, J.P. (1973) Baroreceptor Activity in Normotensive and Hypertensive Uremic Patients. Circulation, 47, 1015-1021. http://dx.doi.org/10.1161/01.CIR.47.5.1015

[37] Tomiyama, O., Shiigai, T., Ideura, T., Tomita, K., Mito, Y., Shinohara, S. and Takeuchi, J. (1980) Baroreflex Sensitivity in Renal Failure. Clinical Science, 58, 21-27. http://dx.doi.org/10.1042/cs0580021

[38] Levin, A., Singer, J., Thompson, C.R., Ross, H. and Lewis, M. (1996) Prevalent Left Ventricular Hypertrophy in the Predialysis Population: Identifying Opportunities for Intervention. American Journal of Kidney Diseases, 27, 347-354. http://dx.doi.org/10.1016/S0272-6386(96)90357-1

[39] Michea, L., Villagran, A., Urzua, A., Kuntsmann, S., Venegas, P., Carrasco, L., Gonzalez, M. and Marusic, E.T. (2008) Mineralocorticoid Receptor Antagonism Attenuates Cardiac Hypertrophy and Prevents Oxidative Stress in Uremic Rats. Hypertension, 52, 295-300. http://dx.doi.org/10.1161/HYPERTENSIONAHA.107.109645

[40] Kingma, J.G., Simard, D., Voisine, P. and Rouleau, J.R. (2014) Impact of Chronic Kidney Disease on Myocardial Blood Flow Regulation in Dogs. Nephron Experimental Nephrology, 126, 175-182. http://dx.doi.org/10.1159/000362090

[41] Papazova, D.A., van Koppen, A., Koeners, M.P., Bleys, R.L., Verhaar, M.C. and Joles, J.A. (2014) Maintenance of Hypertensive Hemodynamics Does Not Depend on ROS in Established Experimental Chronic Kidney Disease. PLoS ONE, 9, e88596. http://dx.doi.org/10.1371/journal.pone.0088596

[42] Hatamizadeh, P., Fonarow, G.C., Budoff, M.J., Darabian, S., Kovesdy, C.P. and Kalantar-Zadeh, K. (2013) Cardiorenal Syndrome: Pathophysiology and Potential Targets for Clinical Management. Nature Reviews Nephrology, 9, 99-111. http://dx.doi.org/10.1038/nrneph.2012.279

[43] Hoshida, S., Yamashita, N., Kawahara, K., Kuzuya, T. and Hori, M. (1999) Amelioration by Quinapril of Myocardial Infarction Induced by Coronary Occlusion/Reperfusion in a Rabbit Model of Atherosclerosis: Possible Mechanisms. 
Circulation, 99, 434-440. http://dx.doi.org/10.1161/01.cir.99.3.434

[44] Hartman, J.C. (1995) The Role of Bradykinin and Nitric Oxide in the Cardioprotective Action of ACE Inhibitors. The Annals of Thoracic Surgery, 60, 789-792. http://dx.doi.org/10.1016/0003-4975(95)00192-N

[45] Hoshida, S., Yamashita, N., Kuzuya, T. and Hori, M. (2000) Differential Effects of Long-Term Renin-Angiotensin System Blockade on Limitation of Infarct Size in Cholesterol-Fed Rabbits. Atherosclerosis, 149, 287-294. http://dx.doi.org/10.1016/S0021-9150(99)00334-2

[46] Downey, J.M. and Cohen, M.V. (1995) Signal Transduction in Ischemic Preconditioning. Zeitschrift fur Kardiologie, 84, 77-86.

[47] Kingma, J.G. (2014) Conditioning Strategies Limit Cellular Injury? World Journal of Cardiovascular Diseases, 4, 539547. http://dx.doi.org/10.4236/wjcd.2014.411065

[48] Ludman, A.J., Yellon, D.M. and Hausenloy, D.J. (2010) Cardiac Preconditioning for Ischaemia: Lost in Translation. Disease Models \& Mechanisms, 3, 35-38. http://dx.doi.org/10.1242/dmm.003855

[49] Kingma Jr., J.G., Vincent, C., Rouleau, J.R. and Kingma, I. (2006) Influence of Acute Renal Failure on Coronary Vasoregulation in Dogs. Journal of the American Society of Nephrology, 17, 1316-1324. http://dx.doi.org/10.1681/ASN.2005101084

[50] Jones, S.P., Tang, X.L., Guo, Y., Steenbergen, C., Lefer, D.J., Kukreja, R.C., Kong, M., Li, Q., Bhushan, S., Zhu, X., Du, J., Nong, Y., Stowers, H.L., Kondo, K., Hunt, G.N., Goodchild, T.T., Orr, A., Chang, C.C., Ockaili, R., Salloum, F.N. and Bolli, R. (2015) The NHLBI-Sponsored Consortium for Preclinical Assessment of Cardioprotective Therapies (CAESAR): A New Paradigm for Rigorous, Accurate, and Reproducible Evaluation of Putative Infarct-Sparing Interventions in Mice, Rabbits, and Pigs. Circulation Research, 116, 572-586. http://dx.doi.org/10.1161/CIRCRESAHA.116.305462

[51] Mehta, P.M., Przyklenk, K. and Kloner, R.A. (1990) Cardioprotective Effects of Captopril in Myocardialischaemia/Reperfusion and Infarction. European Heart Journal, 11, 94-99. http://dx.doi.org/10.1093/eurheartj/11.suppl_B.94

[52] Andrade, T.U., Pinto, V.D., Medeiros, A.R., Abreu, G.R., Moyses, M.R., Sampaio, K.N. and Bissoli, N.S. (2007) Effect of Enalapril Treatment on the Sensitivity of Cardiopulmonary Reflexes in Rats with Myocardial Infarction. Clinical and Experimental Pharmacology and Physiology, 34, 606-611. http://dx.doi.org/10.1111/j.1440-1681.2007.04613.x

[53] Arnold, A.C., Okamoto, L.E., Gamboa, A., Shibao, C., Raj, S.R., Robertson, D. and Biaggioni, I. (2013) Angiotensin II, Independent of Plasma Renin Activity, Contributes to the Hypertension of Autonomic Failure. Hypertension, 61, 701706. http://dx.doi.org/10.1161/HYPERTENSIONAHA.111.00377 